\title{
Gender Differences in Yielding to Social Influence: An Impunity Experiment
}

\author{
Daniela Di Cagno ${ }^{1}$, Arianna Galliera ${ }^{2, *}$, , Werner Güth ${ }^{1,3}$ and Luca Panaccione ${ }^{4}$ \\ 1 Department of Economics and Finance, Luiss Guido Carli, 00197 Rome, Italy; ddicagno@luiss.it (D.D.C.); \\ gueth@coll.mpg.de (W.G.) \\ 2 Department of Management, Economics and Industrial Engineering, Politecnico di Milano, \\ 20156 Milan, Italy \\ 3 Max Planck Institute for Research on Collective Goods, 53113 Bonn, Germany \\ 4 Department of Economics and Finance, University of Rome Tor Vergata, 00133 Rome, Italy; \\ luca.panaccione@uniroma2.it \\ * Correspondence: arianna.galliera@polimi.it; Tel.: +39-02-2399-9531
}

Received: 31 August 2018 ; Accepted: 22 October 2018; Published: 27 October 2018

check for updates

\begin{abstract}
In impunity games proposers, like allocators in dictator games, can take what they want; however, responders can refuse offers deemed unsatisfactory at own cost. We modify the impunity game via allowing offers to condition of another participant's counterfactual generosity intention. For a given pair of proposer candidates each states, via the strategy vector method, an intended and two adjusted offers: one (possibly) upward adjusted in case the intended offer of the other candidate is higher and one (possibly) downward adjusted in case it is lower. Additionally, each candidate determines an acceptance threshold for the responder role. Only one candidate in each pair is randomly selected and endowed as the actual proposer whose offer is either possibly upward or downward adjusted depending on the counterfactual offer of the other proposer candidate. The endowed proposer of one pair is matched with the non-endowed candidate of another pair in the responder role. The data confirm that counterfactual intentions of others often affect own generosity via substantial and significant average adjustments to the weakest social influence. Overall, offers seem correlated with acceptance thresholds. Furthermore, we find significant gender differences: female participants state lower intended and adjusted offers as well as acceptance thresholds and therefore appear to be less sensitive to social influence.
\end{abstract}

Keywords: generosity; impunity game; experiments

JEL Classification: C91; C78; D64

\section{Introduction}

Does one's own generosity depend on the generosity intention of others? In particular, is generosity adapted when learning that an anonymous other would be more or less generous? In this paper, implementing an impunity game, we confirm conditional generosity as well as systematic gender differences in conditioning behavior even after eliminating most of the well known drivers of social influence based on the ability to observe others' behavior. ${ }^{1}$

The impunity game allows us to focus not only on generosity but also on its acceptance. This game, like the dictator game, rules out altruistic sanctioning, observed for the ultimatum game

1 See, e.g., Vesterlund [1]. Of course, gender differences are also explored beyond altruism, e.g., in risk taking (Borghans et al. [2]), cooperation (Rand [3]), and competition (Niederle and Vesterlund [4] and Apicella et al. [5]). 
(see Güth and Kocher [6]), but grants choice of an acceptance threshold and thereby voice to the responder. We implement conditioning on another's counterfactual generosity intention by forming pairs of proposer candidates. Due to the strategy vector method, each proposer states one intended and two adjusted offers: one possibly upward adjusted should the intended offer of the other candidate be higher and one possibly downward adjusted should it be lower. Thus, conditioning is restricted to qualitative information about another candidate's intention. Furthermore, each candidate selects an acceptance threshold for the responder role. After stating offers and thresholds, one random candidate in each pair is endowed and becomes an actual proposer and the other candidate becomes a responder. While proposers and responders are matched across pairs, conditioning occurs within pairs: the actual offer of the proposer is either the (possibly) upward adjusted one or the (possibly) downward adjusted one, depending on whether the other candidate's offer intention is higher or lower. Since only the endowed proposer is responsible for helping the responder, the intended offer of the non-endowed candidate is purely counterfactual but may serve as a basis for conditional generosity.

Participants react to the purely counterfactual generosity intention of a different anonymous other in three successive rounds of playing the game. In addition to conditioning on weak social influence, we investigate gender effects on conditional generosity and its acceptance.

The data confirm that average factual generosity depends on the weak social influence stemming from our modified impunity game: most participants adjust their help level upward as well as downward (see also Di Cagno et al. [7] who explore conditioning in a public good game). Although the majority of donors give more than the minimum, a substantial minority offers only the minimum amount. Interestingly, for most participants the acceptance threshold is significantly lower than their intended and adjusted offers. Furthermore, a majority of offer profiles are adaptive in the sense of reacting to the counterfactual generosity intention of an anonymous participant although a substantial minority of participants is immune to such social influence. When adaptive, one often adapts more downward than upward, i.e., in a self-serving way.

Dictator experiments have analyzed gender differences in altruistic behavior and partly found mixed results. ${ }^{2}$ However, two more recent meta-studies (Rand et al. [13] and Brañas-Garza et al. [14]) more reliably provide evidence that women display more dictator generosity. In contrast, in our conditional impunity game, we find female participants to be less generous than male ones in intended and adjusted offers, but to be more greed tolerant via lower acceptance thresholds. Interpreting one's acceptance threshold as one's individual reference point, our finding suggests that female participants often offer the "needy" more than what they consider as acceptable for themselves, i.e., anchoring on lower thresholds would explain the lower offers of female participants. Overall, female participants appear less sensitive to social influence, but, unlike Rand et al. [13] and Brañas-Garza et al. [14], on average, also less fair than male participants. The latter could be due to employing the strategy vector method in the impunity game that allowed female participants to more strongly rely on their own intuition regarding what to give and what to accept: they give less but are also willing to accept less.

The remainder of the paper is organized as follows: Section 2 describes the experimental design in full detail. Section 3 reports our results and Section 4 provides the conclusions.

\section{Experimental Design and Protocol}

Each pair of proposer candidates consists of one even $(e)$ candidate, whose offers are even integers ranging from $0 €$ to $P_{e}=22 €$, and one odd $(o)$ candidate, whose offers are odd integers ranging from $1 €$ to $P_{o}=23 €$. Before knowing whether actually being monetarily endowed, candidates $e$ and $o$

2 For example, Bolton and Katok [8] found no gender differences, Eckel and Grossman [9] that female participants are more generous and less likely to reject offers, Andreoni and Versterlund [10] that female participants are more generous than male ones, Bruttel and Stolley [11] show that men are more reactive to their responsibility for the receiver's payoff, whereas women react more to strategic power and freedom of choice. For a survey, see Niederle [12]. 
state an offer intention $y_{e}$, respectively, $y_{0}$. Thus, for pairs $(e, o)$ of proposer candidates with different integer restrictions, $y_{e}$ and $y_{o}$ are never equal. Additionally, each candidate $i=e, o$ states two adjusted offers, $y_{i}^{+}$and $y_{i}^{-}$, should the intended offer of the other candidate $j$ be larger $\left(y_{i}<y_{j}\right)$ or smaller $\left(y_{i}>y_{j}\right)$ than the own one. Adjusted offers satisfy the same integer restriction as the intended one. Moreover, $y_{i}^{+}$has to be equal to or larger $\left(y_{i}^{+} \geq y_{i}\right)$ and $y_{i}^{-}$has to be equal to or smaller $\left(y_{i}^{-} \leq y_{i}\right)$ than the own intended offer. The factual offer $y^{i}$ of proposer $i=e, o$ is either the downward adjusted one, $y_{i}^{-}$, when $y_{i}>y_{j}$, or the upward adjusted one, $y_{i}^{+}$, when $y_{i}<y_{j}$. Depending on $i=e, o$, one can guarantee total flexibility in adjusting one's offer via $y_{e}=0$, respectively, $y_{0}=23$, or behave in a purely self contained way via $y_{i}^{-}=y_{i}=y_{i}^{+}$. Due to the strategy vector method, each proposer candidate additionally sets an acceptance threshold $\underline{y}_{i}$ with the same integer restriction for $i=e, o$, relevant when in the role of the responder.

The timeline for eliciting the various components $\left(y_{i}, y_{i}^{+}, y_{i}^{-}, \underline{y}_{i}\right)$ of the individual strategy vectors is illustrated in Figure 1: we first ask for intentions $y_{i}$ before simultaneously letting participants state their adjustments $\left(y_{i}^{+}, y_{i}^{-}\right)$and finally eliciting acceptance thresholds $\left(\underline{y}_{i}\right)$. It is an advantage of impunity games that they, like dictator games, deprive responders of sanctioning power but still grant them choice and voice via stating acceptance thresholds (see for example Xiao and Houser [15] on voice effects). Note, however, that voice via a positive acceptance threshold is costly for the responder in our setup.

\begin{tabular}{|c|c|c|c} 
First choice & Second choice & Third choice & $----\rightarrow$ \\
\hline$y_{i}$ & $y_{i}^{+}$and $y_{i}^{-}$ & $\underline{y}_{i}$
\end{tabular}

Figure 1. Timeline of eliciting the various components of participant $i^{\prime}$ s strategy vector $\left(y_{i}, y_{i}^{+}, y_{i}^{-}, \underline{y}_{i}\right)$.

Only one of the two proposer candidates is randomly (with probability $1 / 2$ ) endowed with $P_{e}$, respectively $P_{0}$. The endowed proposer ( $e$, respectively, $o$ ) confronts as a responder a non-endowed candidate (o, respectively, $e$ ) of another pair, i.e., an even (odd) offer confronts an odd (even) acceptance threshold. The monetary payoff of the endowed proposer $i$ with $i=e, o$ is $P_{i}-y^{i}$, where the factual offer $y^{i}$ is either $y_{i}^{+}$or $y_{i}^{-}$depending on how $y_{i}$ and $y_{j}$ are related. The non-endowed candidate $j$ with $j=e, o$ and $j \neq i$ receives the offer $y^{i}$ by the endowed proposer in another pair and earns $y^{i}$ if $y^{i}>\underline{y}_{j}$ and zero, otherwise. ${ }^{3}$

Due to our focus on differences between sexes in generosity inclinations without strategic concerns, for example in the sense of (altruistic) sanctioning, the subject pool is gender balanced with 36 female and 36 male participants. The computerized, via z-Tree (Fischbacher [16]), experiment was run at LUISS Cesare Lab (Rome) with 72 student participants recruited via Orsee (Greiner [17]). After reading the instructions aloud and allowing participants to privately ask questions, participants were informed about their $i$-type, $i=e, o$.

Participants play three successive rounds of the impunity game with a randomly changing partner in each round. ${ }^{4}$ In each round, two pairs of participants with two $e$ and two $o$ proposer candidates are matched (see the illustration in Figure 2). ${ }^{5}$ The randomly selected endowed proposer $i=e, o$ of one pair confronts the non-endowed candidate $j$ in the other pair, with $j \neq i$, as responder. Thus, the actual offer by proposer $i$ from pair A $\left(y_{A}^{i}\right)$, respectively B $\left(y_{B}^{i}\right)$, is accepted or rejected by responder $j$ of

3 Participants additionally received a show-up fee of 3 euro.

4 Based on rematching groups with four participants, but without informing participants about this restricted rematching. Each proposer candidate is matched with a different one to set the conditional choice and never repeats one round with the same one. No specific restriction was made on the matching between actual proposer and responder.

5 Randomly endowing one candidate of one pair determines also the role of the other pair with respect to be an odd/even player. 
pair B, respectively, A, depending on the stated acceptance threshold. Feedback information between rounds is provided only for the actually interacting participants: proposers learn about acceptance or rejection of their actual offer and responders learn about the offer only in case of acceptance, i.e., when rejecting the offer $y_{i}$ of proposer $i$ due to $y_{i}<\underline{y}_{j}$, responder $j$ learns that $y_{i}$ is smaller than $\underline{y}_{j}$, while when they accept they are informed on the final payoff.

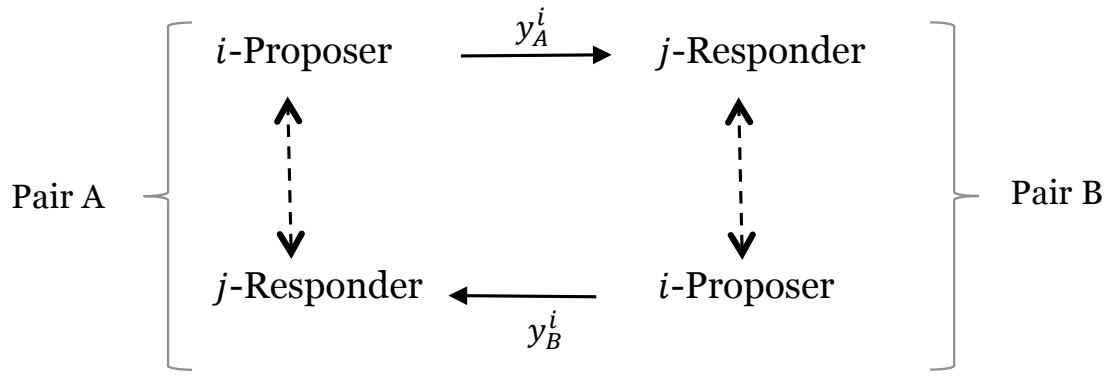

Figure 2. Matching scheme of type $i$ and $j$ proposer candidates in two matched pairs (A and B). Dashed arrows represent the conditional choice relation within each pair (each candidate $i=e, o$ states two adjusted offers, $y_{i}^{+}$and $y_{i}^{-}$, in case the intended offer of the other candidate is larger, $y_{i}<y_{j}$, or smaller, $y_{i}>y_{j}$, than the own one) while actual offers are represented by solid arrows (with $i, j=e, o$ and $i \neq j$ ).

Data come from a more comprehensive experiment (reported in Di Cagno et al. [18]) without the present focus on gender differences, but varying strategic aspects via distinguishing three types of sharing games each played across three rounds, in the order impunity, yes-no and ultimatum game, or vice versa. To avoid any diversification effects, only one (out of nine) randomly selected round has been actually paid. ${ }^{6}$ We focus exclusively on sessions in which participants play the impunity game first. $^{7}$ Altogether we analyze the three strategy profiles $\left(y_{i}, y_{i}^{+}, y_{i}^{-}, y_{i}\right)$ of each participant, hence a total of $72 \times 3=216$ observations for each type of offer as well as for acceptance thresholds.

We expect substantial immunity via no adaptation at all $\left(y_{i}^{-}=y_{i}=y_{i}^{+}\right)$or via excluding the possibility of adaptation to the other's intention (via $y_{e}=0$, respectively, $y_{0}=23$ ), but we predict adaptation to be more dominant (Research Question 1). In line with the related study (Di Cagno et al. [7]), we hope to confirm the previously observed self-servingness of those who adapt, i.e., we expect that average downward adjustments are larger than upwards ones (Research Question 2). Regarding gender differences, we expect to confirm them more systematically. That is, that they do not only appear in single components of the strategy profiles containing altogether four components but show up more systematically in multiple components (Research Question 3). Since we also elicited acceptance thresholds, we investigate if they may be anchors for offers and offer adjustments both in the overall sample and when separated by gender (Research Question 4).

\section{Results}

Participants substantially react to qualitative information about another's intended offer: overall, $58 \%$ of intended offers $y_{i}$ are adjusted, either positively or negatively or both. In particular, $41 \%$ of the adjustments are both upward and downward $\left(y_{i}^{-}<y_{i}<y_{i}^{+}\right), 34 \%$ only downward $\left(y_{i}^{-}<y_{i}=y_{i}^{+}\right)$ and $25 \%$ only upward $\left(y_{i}^{-}=y_{i}<y_{i}^{+}\right)$.

Result 1. More than half of all offer profiles react to qualitative information about the (purely counterfactual) intended offer of the other candidate. Among adjusted offers, the largest share adjusts in both directions but significant proportions of offer profiles adjust only downward, respectively upward.

6 The translated instructions for the impunity game are reported in Appendix A.

7 Sessions are not gender-balanced to avoid possible demand effects which could arise from participants' awareness of such a balance. 
Pooling offer profiles $\left(y_{i}, y_{i}^{+}, y_{i}^{-}\right)$across participants and rounds finds the average intended offer $y$ to be significantly smaller than $y^{+}$and greater than $y^{-}$(Table 1 ). Both (non-negative) differences $y^{+}-y$ and $y-y^{-}$are substantial and significantly positive, but $y-y^{-}$is significantly larger (2.398) than $y^{+}-y(1.630)$ due to the paired $t$-test $p$-value $=0.031$ for the whole sample. Overall, the marked downward adjustment may reveal a "sucker effect": proposer candidates more substantially reduce their offer when reacting downwards than upwards.

Table 1. Average offers $\left(y, y^{+}, y^{-}\right)$, threshold $(\underline{y})$ and differences $\left(y^{+}-y, y-y^{-}\right)$with paired $t$-tests.

\begin{tabular}{lccccccc}
\hline & $y$ & $y^{+}$ & $y^{-}$ & $\underline{y}$ & $y^{+}-y$ & $y-y^{-}$ & $y-\underline{y}$ \\
\hline Mean & 5.361 & 6.991 & 2.963 & 2.176 & 1.630 & 2.398 & 3.185 \\
Std. Dev. & 6.123 & 7.268 & 3.929 & 2.173 & 3.212 & 4.344 & 5.706 \\
Min & 0 & 0 & 0 & 0 & 0 & 0 & -10 \\
Max & 23 & 23 & 22 & 13 & 20 & 22 & 22 \\
\hline \multicolumn{7}{c}{ Paired $t$-test } \\
& & $\left(H 0: y=y^{+}\right)$ & $\left(H 0: y=y^{-}\right)$ & $(H 0: y=\underline{y})$ & $\left(H 0: y^{+}-y=y-y^{-}\right)$ \\
\hline$p$-value & 0.000 & 0.000 & 0.000 & \multicolumn{3}{c}{0.031} \\
\hline
\end{tabular}

Notes: the results are based on 216 observations. Average $y, y^{+}$and $y^{-}$and paired $t$-test $p$-values are reported.

Result 2. Average differences $\left(y^{+}-y\right.$ and $\left.y-y^{-}\right)$are substantial and significantly different ( $t$-test $p$-value $=0.031$. Upward and downward adjustments are, in a self-serving way, more downward biased.

Consistent with Result 2, the distribution of downward adjusted offers $y^{-}$is more concentrated towards lower offers (Figure 3), than the distribution of upward adjusted offers $y^{+}$(Figure 4) and the one of intended offers $y$ (Figure 5).

The average acceptance threshold $y$ is significantly lower than the intended offer $y(p$-value $<0.01)$ : on average, participants offer more than what they are willing to accept.

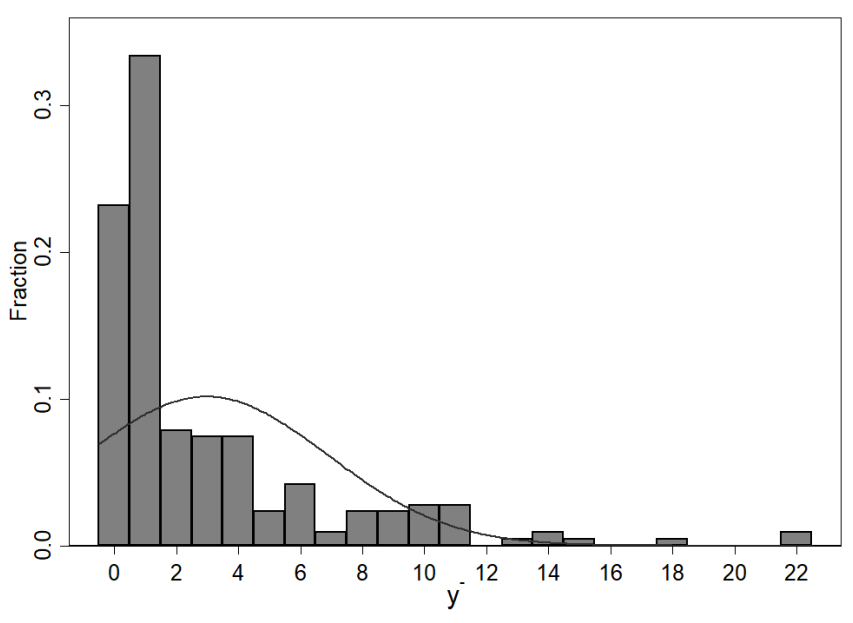

Figure 3. Distribution of average downward adjusted offer $y^{-}$. 


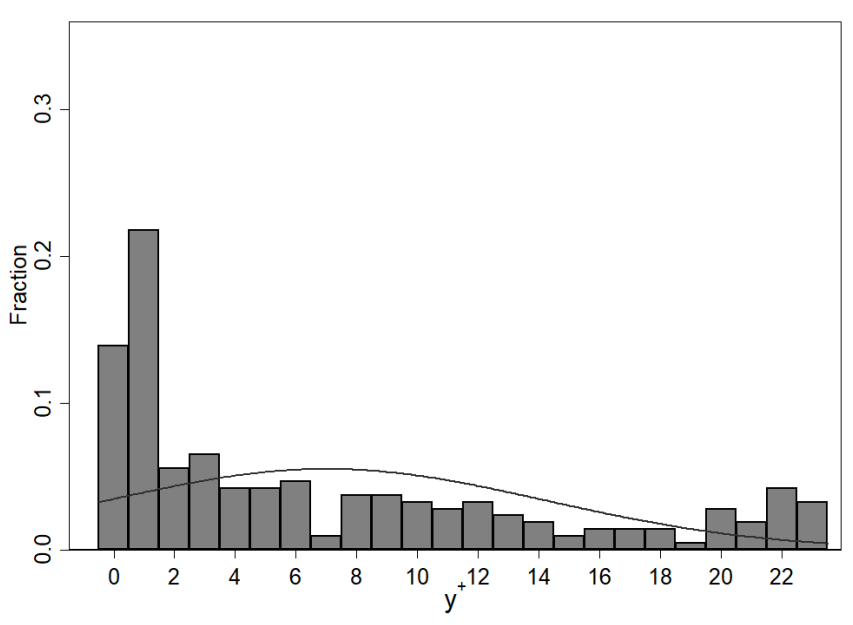

Figure 4. Distribution of average upward adjusted offer $y^{+}$.

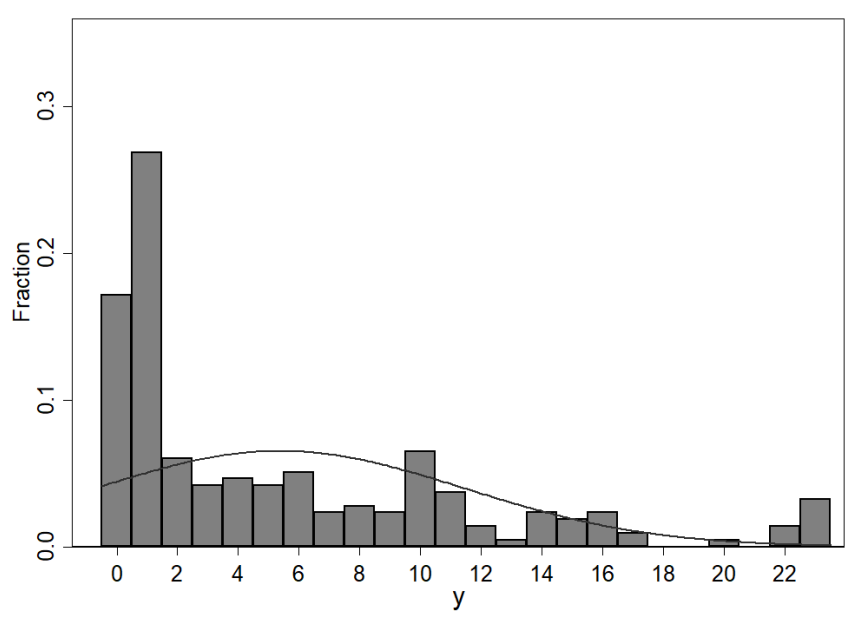

Figure 5. Distribution of average intended offer $y$.

\section{Gender Effects}

The strategy profiles, each containing four components, reveal systematic gender effects: female participants display lower generosity intentions $(y)$, lower upward adjusted offers $\left(y^{+}\right)$and also significantly lower acceptance thresholds $(y)$ than male participants. Only for $y^{-}$there is no significant sex difference (see Table 2). To check whether this is related to the censored distribution of $y^{-}$by 0 (or 1) we exclude the minimum values (see columns $y^{-}(>1)$ in Table 2): for this restricted data set, male participants set $y^{-}$higher than female ones but $y^{-}>1$ occurs less often. The overall adaptation $y^{+}-y^{-}$is significantly larger for male participants meaning that they are more sensitive to the weakest social influence than female ones.

Table 2. Average offers and threshold with gender paired $t$-tests.

\begin{tabular}{|c|c|c|c|c|c|c|c|c|c|c|c|c|}
\hline & \multicolumn{2}{|c|}{$y$} & \multicolumn{2}{|c|}{$y^{+}$} & \multicolumn{2}{|c|}{$y^{-}$} & \multicolumn{2}{|c|}{$y^{-}(>1)$} & \multicolumn{2}{|c|}{$y^{+}-y^{-}$} & \multicolumn{2}{|c|}{$\underline{y}$} \\
\hline & Male & Female & Male & Female & Male & Female & Male & Female & Male & Female & Male & Female \\
\hline Mean & 6.491 & 4.231 & 8.194 & 5.787 & 3.269 & 2.657 & 7.136 & 5.080 & 4.926 & 3.130 & 2.602 & 1.750 \\
\hline Std. Dev. & 7.392 & 4.255 & 8.244 & 5.936 & 4.623 & 3.076 & 5.197 & 3.036 & 6.496 & 4.377 & 3.318 & 2.019 \\
\hline obs & 108 & 108 & 108 & 108 & 108 & 108 & 44 & 54 & 108 & 108 & 108 & 108 \\
\hline & \multicolumn{12}{|c|}{ Paired $t$-test $\left(H 0: y_{\text {male }}=y_{\text {female }}\right)$} \\
\hline$p$-value & \multicolumn{2}{|c|}{0.006} & \multicolumn{2}{|c|}{0.015} & \multicolumn{2}{|c|}{0.254} & \multicolumn{2}{|c|}{0.020} & \multicolumn{2}{|c|}{0.018} & \multicolumn{2}{|c|}{0.024} \\
\hline
\end{tabular}


Result 3. Male participants reveal more fairness and stronger sensitivity to social influence than female participants by higher offer intentions (y), respectively, by reacting more strongly to counterfactual offers; symmetrically, they are less willing as responders to accept low offers (via y).

Figures 6-8 reporting the distribution of offers $\left(y, y^{+}, y^{-}\right)$by sex confirm that female participants display lower generosity intentions, i.e., distributions of offers for female subjects are more concentrated on lower values compared to those for male subjects. Figures 6 and 7 reveal that male participants generate larger outliers than female participants. When we exclude the data larger than the 90th percentile for both male and female offer intention (to reduce the effect of possible outliers in the gender discrepancy), the average male offer (4.7 tokens) is significantly higher than the female one (2.8 tokens).

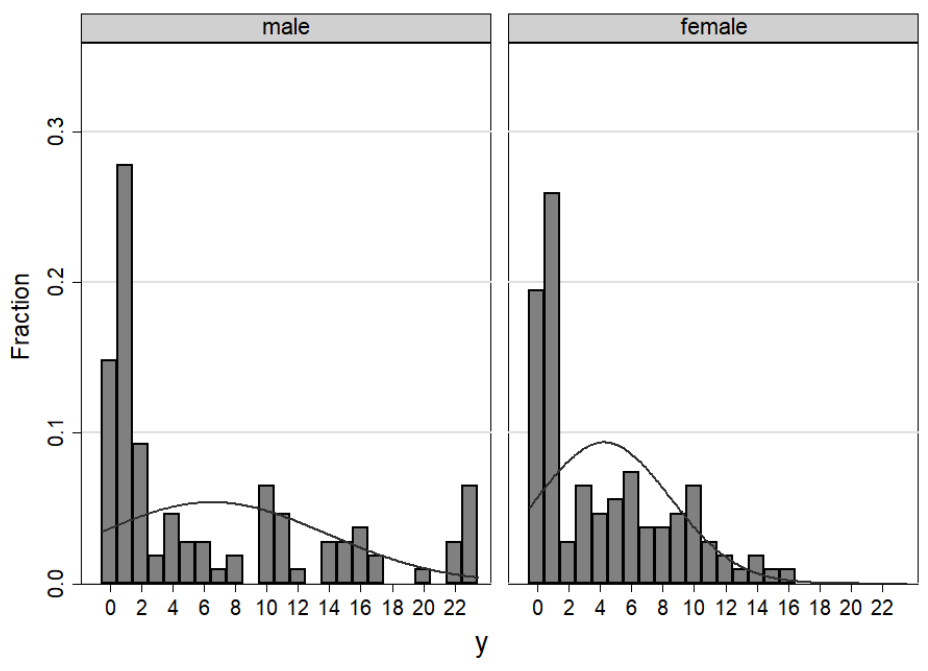

Figure 6. Distribution of average intended offer $y$ by sex.

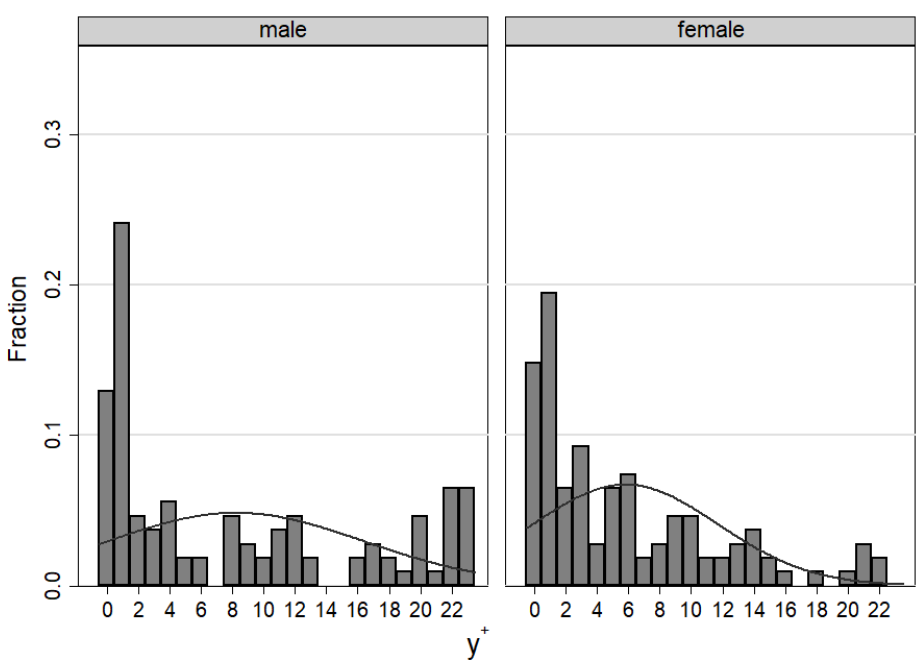

Figure 7. Distribution of average upward adjusted offer $y^{+}$by sex. 


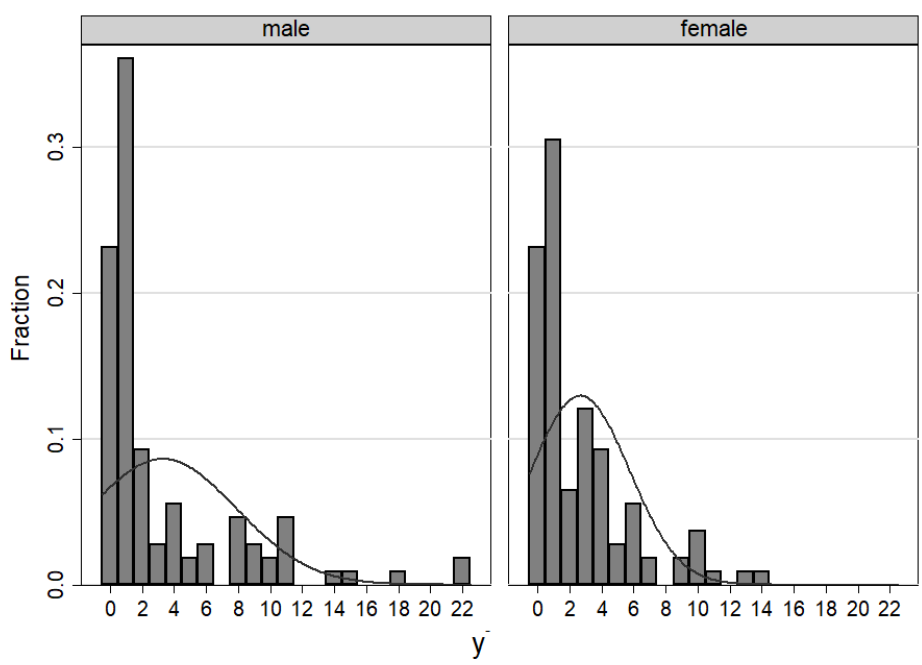

Figure 8. Distribution of average downward adjusted offer $y^{-}$by sex.

Table 3 reports the relative frequency of $\left(y_{i} \geq \underline{y}_{i}\right)$, i.e., instances of accepting one's own offer intention. In the majority of cases $(93.5 \%$ for male participants and $87 \%$ for female ones), offers are equal to or larger than acceptance thresholds, i.e., one intends to offer at least as much as what one would accept. The offer profiles displaying $y_{i}<y_{i}$ suggests that female subjects more likely refuse their own offer (13\%) than male subjects (6.5\%). The average level, $|y-y|$, of absolute consistency, i.e., of equal offer intention and acceptance threshold $\left(y_{i}=\underline{y}_{i}\right)$, is only slightly lower for female than for male participants.

Result 4. Most of the male and female participants are willing to accept at least their own intended offers and anchor them on their acceptance thresholds.

Using the strategy vector method for the impunity game may suggest a possible correlation or anchoring of intended offers and acceptance thresholds. The fact that female participants are less generous and less likely refuse an offer as a responder than male participants may be due to their lower acceptance thresholds on which their intended offers and adjustments are anchored.

Table 3. Gender effect in internal consistency.

\begin{tabular}{lccccc}
\hline & $\%\left(y_{i}<\underline{y}_{i}\right)$ & $\%\left(y_{i}=\underline{y}_{i}\right)$ & $\%\left(y_{i}>\underline{y}_{i}\right)$ & $(y-\underline{y})$ & $|y-\underline{y}|$ \\
\hline Male & 6.5 & 43.5 & 50.0 & 3.889 & 4.407 \\
Female & 13.0 & 40.7 & 46.3 & 2.500 & 3.148 \\
\hline \multicolumn{5}{c}{ Paired $t$-test $\left(H 0: y_{\text {male }}=y_{\text {female }}\right)$} \\
\hline$p$-value & \multicolumn{4}{c}{0.070} & 0.083 \\
\hline
\end{tabular}

\section{Conclusions}

Analyzing social influence via an amended impunity experiment without competition in helping has provided robust evidence for the weakest social influence on intrinsic generosity. ${ }^{8}$ Most participants condition their offers on purely counterfactual intentions of one anonymous other with whom they do not interact, even though a substantial minority of offer profiles is immune to social

8 A related work is d'Adda et al. [19] where authors find that dictators respond to social influence (although they do not analyse conditioning and gender differences). 
influence. While there may be stable intrinsic generosity inclinations, what dominates is adaptation to others' intentions. ${ }^{9}$

Significant gender effects in this setup are that female participants are less generous and less sensitive to social influence than male ones. This is revealed by intended offers, offer adjustments and acceptance thresholds. Both male and female participants overwhelmingly are willing to accept at least their own intended offer and seem to anchor intended offers on their acceptance thresholds although $13 \%$ and thus about twice as many female subjects than male subjects $(6.5 \%)$ would not accept their own intended offer. Male participants are more generous, more sensitive to others' intentions (i.e., adjust more strongly) and choose higher acceptance thresholds than female participants.

In our view, detecting gender effects in multi-dimensional choice vectors, like when employing the strategy vector method, allows for confirming gender differences more systematically, which might shed light on when and why they can be expected. Our finding that female participants choose lower thresholds than male ones, i.e., are willing to accept lower offers, is consistent, for instance, with the field and lab evidence of women accepting lower wages in the labor market (see Azmat and Petrongolo [20] who review experimental evidence). Anchoring their own offers on their lower acceptance thresholds could explain why female participants are less generous in the proposer role by arguing: "if I am willing to accept less, then why should I offer more than that?". Thus, anchoring on acceptance thresholds when determining one's generosity in the proposer role could account for the systematic gender differences which are reported and analyzed above.

Author Contributions: All author contributed equally to this article.

Funding: The research in this paper was financed by the Max Planck Institute for Research on Collective Goods, Bonn, Germany.

Conflicts of Interest: The authors declare no conflict of interest. The founding sponsors had no role in the design of the study; in the collection, analyses, or interpretation of data; in the writing of the manuscript, and in the decision to publish the results.

\section{Appendix A}

\section{Instructions to Participants}

\section{Introduction}

Welcome to our experiment! During this experiment, you as well as the other participants will have to take several decisions. Please read the instructions carefully. Your decisions, as well as the decisions of the other participants will determine your payoff according to rules, which will be explained shortly. The earnings during the experiment are expressed in euros $(€)$. In addition to the earnings obtained over the course of the experiment, you will receive a show-up fee of $€ 3.00$. Please note that hereafter any form of communication between the participants is strictly prohibited. If you violate this rule, you will be excluded from the experiment with no payment. If you have any questions, please raise your hand. The experimenter will come to you and answer your questions individually.

\section{Description of the Experiment}

This experiment is fully computerized. After reading the instructions, before starting the experimental task, you will have to answer to few control questions; these questions are going to help you to understand the experimental task, and they have no effect on your final earnings.

9 Our companion study (Di Cagno et al. [18]) does not focus on gender effects but on how weakest social influence is moderated by sanctioning in sharing games with and without monitoring proposer generosity as well as by experience with such games. Both studies together confirm Results 1 and 2. 
The experiment is composed by 5 control questions (to help you understanding the experiment), three phases (Phase I, Phase II and Phase III) and a final questionnaire. Each phase lasts 3 rounds and in each round you can be a proposer or a responder. Your role will be randomly selected by the computer with probability equal to $1 / 2$ and communicated at the end of each round.

The proposer will be endowed with an initial amount of euros which can be shared with a responder in the experiment. A responder will have no endowment and can accept or reject the offer of the proposer.

Note: Your task in each round is to make choices that pertain your role as a proposer and your role as a responder. Beware that you will have to take your decisions before knowing if you will be a proposer or a responder.

\section{Phase I}

At the beginning of each round in Phase I, you will be selected either as $O(\mathrm{dd})$ participant or as an $E$ (ven) participant with probability $1 / 2$. If you are $E$ your initial endowment is $€ 22$ and you can allocate only even values. If you are $O$ your initial endowment is $€ 23$ and you can allocate only odd values. After that, you will be randomly paired with another participant, whose identity will not be disclosed to you. If you are an $O(\mathrm{dd})$ participant, you will be paired with an $E$ (ven) participant; similarly, if you are an $E$ (ven) participant, you will be paired with an $O(\mathrm{dd})$ participant. The paired participant will always be different from the one in the previous round.

Both you and your paired participant are asked to take the following decisions:

1. first, you have to decide, individually and independently, how much of your endowment you to want to give to a responder (different from your paired participant) if you will be selected as a proposer. If you are an $O(\mathrm{dd})$ participant, you can choose one between these numbers $\{1,3, \ldots, 21,23\}$. If you are an $E$ (ven) participant, you can choose one of the numbers $\{0,2,4, \ldots, 20,22\}$.

Observe that both types of participants have the same number of possible choices, i.e., twelve, and that the difference between the minimum and the maximum choice, i.e., $22 €$, is the same for both types of participant.

2. Second, you have to decide, individually and independently, how much you want to update your initial proposal if you will be selected as a proposer in the two following situations:

- the proposal of your paired participant is larger than yours; in this case you can either confirm or increase your initial proposal;

- the proposal of your paired participant is smaller than your; in this case you can either confirm or decrease your initial proposal.

Remember that in each of the two cases, your updated proposal can only be an odd number or even number depending on whether you are an $O$ or an $E$ candidate.

Note: Beware that you will be asked to update your initial proposal before knowing if the other has decided to propose more than you or less than you.

3. Third, you have to decide, individually and independently, what proposals you will accept if you will be selected as a responder. In particular, you have to decide an acceptance threshold such that all proposals larger than the threshold will be accepted and all proposals lower than the threshold will be rejected.

Remember that the acceptance threshold can only be an odd number or even number depending on whether you are an $O$ or an $E$ candidate.

After all participants have taken their decisions regarding the initial proposal, the updated proposals and the acceptance threshold, the computer will 
- adjust the proposals of each participant depending on whether the initial proposal of the paired participant is larger or smaller than the own one;

- $\quad$ select, for each pair of participant, who is the proposer and who is the responder;

- randomly match each proposer with a responder from a different pair than the initial one and, similarly, randomly match each responder with a proposer from a different pair than the initial one.

Observe that:

- $O(\mathrm{dd})$ proposers will be matched with $E(\mathrm{ven})$ receivers and that $E(\mathrm{ven})$ proposers will be matched with $O(\mathrm{dd})$ receivers;

- the proposal communicated to the receiver will be the adjusted one (and not the initial one).

Your payoff in Phase I will be calculated as follows:

- if you are a proposer, your payoff will be equal to your endowment minus your offer both in case the offer is above or below the responder's acceptance threshold.

- if you are a receiver, your payoff will be equal to

- the proposer's proposal if this is larger than your acceptance threshold;

- equal to zero if the proposal is smaller than your acceptance threshold.

Summing up, at the end of each round the computer communicates:

- $\quad$ if you are proposer or responder;

- $\quad$ if your are a proposer, you will be communicated that you were selected as a proposer and you will be informed about your final payoff and the payoff of the responder who received your proposal;

- if you are a receiver, you will be communicated that you were selected as a receiver and you will be informed about your final payoff.

Note: The computer will not inform you about the initial proposal of the paired participant with whom you interact at the beginning of each round.

\section{References}

1. Vesterlund, L. Using Experimental Methods to Understand Why and How We Give to Charity. In The Handbook of Experimental Economics; Kagel, J.H., Roth, A.E., Eds.; Princeton University Press: Princeton, NJ, USA, 2016; Volume 2.

2. Borghans, L.; Golsteyn, B.; Heckman, J.; Meijers, H. Gender differences in risk aversion and ambiguity aversion. J. Econ. Eur. Assoc. 2009, 7, 649-658. [CrossRef]

3. Rand, D. Social dilemma cooperation (unlike Dictator Game giving) is intuitive for men as well as women. J. Exp. Soc. Psycol. 2017, 73, 164-168. [CrossRef] [PubMed]

4. Niederle, M.; Vesterlund, L. Do women shy away from competition? Do men compete too much? Q. J. Econ. 2007, 122, 1067-1101. [CrossRef]

5. Apicella, C.L.; Demiral, E.E.; Mollerstrom, J. No Gender Difference in Willingness to Compete When Competing against Self. Am. Econ. Rev. 2017, 107, 136-140. [CrossRef]

6. Güth, W.; Kocher, M.G. More than thirty years of ultimatum bargaining experiments: Motives, variations, and a survey of the recent literature. J. Econ. Behav. Organ. 2014, 108, 396-409. [CrossRef]

7. Di Cagno, D.; Galliera, A.; Güth, W.; Panaccione, L. A hybrid public good experiment eliciting multi-dimensional choice data. J. Econ. Psychol. 2016, 56, 20-38. [CrossRef]

8. Bolton, G.E.; Katok, E. An experimental test for gender differences in beneficent behavior. Econ. Lett. 1995, 48, 287-292. [CrossRef]

9. Eckel, C.C.; Grossman, P.J. Are women less selfish than men?: Evidence from dictator experiments. Econ. J. 1998, 108, 726-735. [CrossRef] 
10. Andreoni, J.; Vesterlund, L. Which is the fair sex? Gender differences in altruism. Q. J. Econ. 2001, 116, 293-312. [CrossRef]

11. Bruttel, L.; Stolley, F. Gender Differences in the Responce to Decision Power and Responsability-Framings Effects in a Dictator Game. Games 2018, 9, 28. [CrossRef]

12. Niederle, M. Gender. In The Handbook of Experimental Economics; Kagel, J.H., Roth, A.E., Eds.; Princeton University Press: Princeton, NJ, USA, 2016; Volume 2.

13. Rand, D.; Brescoll, V.; Everett, J.; Capraro, V.; Barcelo, H. Social heuristics and social roles: Intuition favors altruism for women but not for men. J. Exp. Psycol. Gen. 2016, 145, 389-396. [CrossRef] [PubMed]

14. Brañas-Garza, P.; Capraro, V.; Rascón-Ramírez, E. Gender differences in altruism on Mechanical Turk: Expectations and actual behavior. Econ. Lett. 2018, 170, 19-23. [CrossRef]

15. Xiao, E.; Houser, D. Emotion Expression in Human Punishment Behavior. Proc. Natl. Acad. Sci. USA 2005, 102, 7398-7401. [CrossRef] [PubMed]

16. Fischbacher, U. z-Tree: Zurich toolbox for ready-made economic experiments. Exp. Econ. 2007, 10, 171-178. [CrossRef]

17. Greiner, B. Subject Pool Recruitment Procedures: Organizing Experiments with ORSEE. J. Econ. Sci. Assoc. 2015, 1, 114-125. [CrossRef]

18. Di Cagno, D.; Galliera, A.; Güth, W.; Panaccione, L. Intention-Based Sharing. Games 2018, 9, 22. [CrossRef]

19. D'Adda, G.; Capraro, V.; Tavoni, M. Push, don't nudge: Behavioral spillovers and policy instruments. Econ. Lett. 2017, 154, 92-95. [CrossRef]

20. Azmat, G.; Petrongolo, B. Gender and the labor market: What we have learned from field and lab experiments? Labor Econ. 2014, 30, 32-40. [CrossRef]

(C) 2018 by the authors. Licensee MDPI, Basel, Switzerland. This article is an open access article distributed under the terms and conditions of the Creative Commons Attribution (CC BY) license (http:/ / creativecommons.org/licenses/by/4.0/). 